\title{
ARTIGO
}

\section{Trabalhador autônomo exclusivo: maior segurança jurídica para o contratante ou melhor disfarce para a relação de emprego?}

Exclusive independent contractor: greater legal certainty for the contracting party or better disguise for the employment relationship?

Trabajador autónomo exclusivo: ¿mayor seguridad jurídica para el contratante o mejor disfraz para la relación de empleo?

\section{Diego Pinto de Barros Leal ${ }^{1}$}

RESUMO: A Reforma Trabalhista, aprovada no Congresso Nacional em caráter de urgência e sem debate qualificado, criou o trabalhador autônomo exclusivo e, com ele, a incerteza acerca de seu real significado no mundo do trabalho, que tanto pode ser o de conferir maior segurança jurídica ao contratante como o de legalizar a chamada pejotização, fenômeno de desvirtuamento da relação de emprego por meio da transformação de um empregado em prestador de serviços sob a forma de pessoa jurídica. Diante desse cenário, recorrendo à pesquisa bibliográfica, este trabalho analisa se existe risco de precarização dos direitos dos trabalhadores e, existindo, verificar qual seria o seu reflexo no sistema previdenciário. Também examina os pressupostos individualizadores dessa nova figura jurídica em contraposição com os requisitos da relação de emprego para, com isso, delimitar a sua aplicabilidade e estabelecer a sua harmonização com as demais modalidades de trabalho, concluindo que está restrita a situações específicas, não podendo o desígnio do legislador ser compreendido como uma legalização da pejotização, e sim como uma tentativa de conferir maior segurança jurídica aos contratantes.

Palavras-chave: Trabalhador Autônomo Exclusivo; Reforma Trabalhista; Pejotização; Relação de Emprego.

1 Bacharel em Direito pela Universidade Federal do Ceará. Especialista em Direito Processual pela Faculdade de Tecnologia Darcy Ribeiro e em Direito do Trabalho pela Faculdade de Paraíso do Norte. Auditor-Fiscal do Trabalho lotado na Gerência Regional do Trabalho de Juazeiro. 
ABSTRACT: The Labor Reform, approved by the National Congress as a matter of urgency and without qualified debate, created the exclusive independent contractor and, with it, the uncertainty about its real meaning in the labor world, which can be either to give greater legal certainty to the contracting party or to legalize the socalled "pejotização", phenomenon which distorts the employment relationship by shifting an employee into a service provider masked as a legal entity. In view of this scenario, using bibliographic search, this paper analyzes whether there is a risk of weakening workers' rights and, if there is one, to verify what its impact on the social security system would be. Also examines the individualizing presuppositions of this new legal figure opposed to the employment relationship's characteristics in order to delimit its applicability and establish its harmonization with the other work modalities, concluding that it is restricted to specific situations and that the legislator's purpose cannot be understood as the legalization of "pejotização", but as an attempt to grant the contractors greater legal certainty.

Keywords: Exclusive Independent Contractor; Labor Reform; "Pejotização"; Employment Relationship.

\section{INTRODUÇÃO}

A Reforma Trabalhista, entabulada pela Lei Federal $n^{\circ}$. 13.467/2017, fez surgir o trabalhador autônomo exclusivo, cuja criação pode ser compreendida tanto como uma tentativa de burla ao vínculo empregatício quanto como um mecanismo de fortalecimento do trabalho autônomo. $\mathrm{O}$ artigo 442-B da Consolidação das Leis do Trabalho - CLT, originado pela Reforma, permite a contratação de profissional que poderá prestar serviços de maneira contínua e para apenas uma empresa sem que haja a configuração de relação empregatícia.

Há quem critique a inovação por cogitar que esta facilita a pejotização, fenômeno de desvirtuamento da relação de emprego por meio da transformação de um empregado em prestador de serviços sob a forma de pessoa jurídica, carente de direitos e garantias típicas de um assalariado, para redução de encargos de responsabilidade da empresa contratante.

Por outro lado, os defensores da mudança legislativa afirmam que ela não legaliza a pejotização, mas confere segurança jurídica àqueles que optarem por contratar trabalhador autônomo de modo exclusivo, uma vez que a exclusividade, malgrado não seja um requisito do vínculo de emprego, era tida como elemento para a formação de convicção quanto à existência ou não desse liame. 
Vale destacar que os artigos $2^{\circ}$, caput, e $3^{\circ}$, caput, da CLT, que definem, respectivamente, os conceitos de empregador e empregado, não sofreram alterações, ou seja, os elementos caracterizadores da relação empregatícia continuam sendo pessoalidade, trabalho por pessoa física, não eventualidade, onerosidade e subordinação.

Em vista disso, a legitimação da figura do trabalhador autônomo exclusivo, com a sua inserção no diploma celetista por intermédio de atividade legiferante conduzida em uma conjuntura política propícia, é assimilada com exegese sistemática e teleológica dos pressupostos intrínsecos e extrínsecos que definem esse tipo de trabalhador, cotejados com disposições legais à luz de princípios norteadores do direito do trabalho, de modo a não provocar a sua difusão de forma indiscriminada e causar prejuízo à classe trabalhadora.

\section{O SURGIMENTO DO TRABALHO AUTÔNOMO EXCLUSIVO}

O mundo está em constante transformação. Assim, nada mais natural que as normas, que regem relações interpessoais, inclusive no âmbito laboral, sejam modificadas com o passar do tempo para a sua adaptação à dinâmica social. A Reforma Trabalhista, obviamente encaixada nesse contexto, trouxe uma quebra de paradigmas, na medida em que regras, por muito tempo vigentes, foram extintas ou substituídas e outras, até então inexistentes, positivadas, como o trabalho autônomo exclusivo, inserto no novel artigo 442-B da CLT.

Uma das maiores críticas à Reforma está relacionada, sem dúvida, à sua aprovação em caráter de urgência no Congresso Nacional, prática inconciliável com a quantidade de alterações que promoveu, sem debate qualificado, no ordenamento jurídico trabalhista, tanto que alguns de seus dispositivos tiveram as constitucionalidades questionadas ao Supremo Tribunal Federal $-\mathrm{STF}^{2}$.

No Senado Federal, a tramitação do projeto de lei respectivo ${ }^{3}$ ocorreu sem quaisquer ressalvas, em nítido propósito de conferir, o quanto antes, vigência à norma em

\footnotetext{
2 Até maio de 2019, pelo menos trinta ações diretas de inconstitucionalidade tinham sido propostas perante o STF para questionamento de dez pontos controversos da Reforma Trabalhista. Fonte: Saad, José Eduardo Duarte. Tabela das ADINs - Reforma Trabalhista. Disponível em: http://www.saadadvocacia.com.br/publicacoes/noticias/69tabela-das-adins-reforma-trabalhista. Acesso em: 6 jul. 2019.

3 A Reforma Trabalhista, vigente a partir de 11 de novembro de 2017, após cumprir vacatio legis de cento e vinte dias, tramitou na Câmara dos Deputados por meio do Projeto de Lei no. 6.787/2016, acatado no Plenário em 26 de abril de 2017. Em seguida, a proposta seguiu para o Senado Federal, onde ficou conhecida como Projeto de Lei da Câmara - PLC no. 38/2017, com aprovação no dia 11 de julho de 2017 . O texto foi sancionado sem vetos pelo então Presidente da República Michel Temer em 13 de julho de 2017 e a sua publicação oficial ocorreu no dia seguinte.
} 
comento. O líder do Governo, à época, ex-Senador Romero Jucá, comunicou aos senadores que o Presidente da República havia feito um compromisso de promover mudanças nos pontos mais controversos da proposta, entre os quais o que previa a possibilidade de cláusula de exclusividade para trabalhadores autônomos ${ }^{4}$.

Por esse motivo, foi lançada a Medida Provisória $n^{\circ}$. 808, de 14 de novembro de 2017, sob o seguinte argumento ${ }^{5}$ :

Disto isto, a presente proposta de Medida Provisória tem por objetivo o aprimoramento de dispositivos pontuais, relacionados a aspectos discutidos durante a tramitação do PLC nº. 38, de 2017, no Senado Federal. Se, por um lado, tais aspectos refletem o profundo processo de diálogo e análise realizado pelo Senado Federal, por outro, esta Casa Legislativa observou a desnecessidade de alteração do projeto no momento de sua tramitação, o que implicaria atrasos desnecessários à eficácia deste importante diploma legal. É neste sentido que, como consequência da atuação do Senado Federal, e sem maiores atrasos, aguardamos a entrada em eficácia da Lei $n^{\circ}$. 13.467, de 2017, na data de 11 de novembro de 2017.

Desse modo, houve o acréscimo de sete parágrafos ao artigo 442-B da CLT com a pretensão, segundo a Exposição de Motivos no . 00023/2017 do Ministro de Estado do Trabalho, de conferir maior clareza e segurança jurídica à contratação do trabalhador autônomo, vedando cláusula de exclusividade em contratos dessa natureza. Houve, também, a inclusão de comando que reconhecia o vínculo empregatício caso estivesse presente a subordinação jurídica.

No entanto, essa Medida Provisória, mesmo tendo recebido novecentas e sessenta e sete emendas, perdeu validade no dia 23 de abril de 2018, não tendo sido sequer apreciada pela comissão mista, a qual não chegou a ter relator eleito ${ }^{6}$. Por conseguinte, o artigo 442-B da CLT tornou, a partir daí, a ter a sua redação original e sem parágrafos.

4 Portal de Notícias G1. Senado aprova reforma trabalhista; texto segue para sanção de Temer. Disponível em: https://g1.globo.com/politica/noticia/apos-sessao-tumultuada-senado-aprova-texto-base-da-reformatrabalhista.ghtml. Acesso em: 7 jul. 2019.

5 Brasil. Exposição de Motivos no. 00023/2017 do Ministro de Estado do Trabalho. Disponível em: http://www.planalto.gov.br/ccivil 03/ Ato2015-2018/2017/Mpv/mpv808.htm. Acesso em: 7 jul. 2019.

6 Agência Senado. Medida Provisória que altera reforma trabalhista perde a validade nesta segunda. Disponivel em: https://www12.senado.leg.br/noticias/materias/2018/04/20/medida-provisoria-que-altera-reformatrabalhista-perde-a-validade-nesta-segunda. Acesso em: 14 jul. 2019. 
Posteriormente, com base no artigo 87, parágrafo único, inciso II, da Constituição Federal, foi publicada, pelo Ministro de Estado do Trabalho, a Portaria ${ }^{\circ} .349$, de 23 de maio de 2018, a pretexto de estabelecer regras voltadas à execução da Reforma Trabalhista. Na verdade, o plano era o de amenizar a caducidade da medida provisória mencionada. Com efeito, foi declarado, novamente, que, presente a subordinação jurídica, seria reconhecido o vínculo empregatício.

\section{O RISCO DE AUMENTO DA PEJOTIZAÇÃO COM A LEGITIMAÇÃO DO TRABALHO AUTÔNOMO EXCLUSIVO}

Antônio Silva Neto, que ocupou cargo de Assessor Jurídico do ex-Deputado Rogério Marinho, relator da Reforma Trabalhista na Câmara dos Deputados, avalia que a instituição do trabalho autônomo exclusivo não incentiva a pejotização. Ilustra a sua afirmação com o exemplo de um caminhoneiro que tivesse dificuldade de conseguir viagens e, então, oferecesse os seus serviços para uma transportadora mediante a assinatura de um contrato.

Esse caminhoneiro poderia fazer o que quisesse, dirigir pelo tempo que achasse melhor e escolher onde parar, posto que, por não ser subordinado à empresa contratante, não poderia receber ordens dela ou ter o seu trabalho gerenciado ou controlado. $\mathrm{O}$ trabalhador atuaria com total independência, em razão de o importante ser a entrega dos resultados, qual seja, a entrega da carga no local e dia previamente designados ${ }^{7}$.

Entretanto, para Rodrigo Britto, presidente da CUT Brasília, o advento do trabalho autônomo exclusivo seria um subterfúgio para burlar a carteira de trabalho e legalizar a pejotização. $O$ problema seria o profissional trabalhar com subordinação de empregado, mas utilizando uma pessoa jurídica. Se ele tivesse algum afastamento temporário, ficaria sem respaldo da legislação laboral, por ter sido travada uma relação comercial. A tendência seria de aumento da pejotização para fuga de direitos e garantias previstas por lei ou instrumento coletivo de trabalho ${ }^{8}$.

Na pejotização, o trabalhador subordinado deixa de ser contratado como pessoa física e passa a ser contratado como pessoa jurídica, porém sem os mesmos direitos assegurados a um empregado. Na lição de Krein (2018, p. 104):

7 Sousa, Valdivino. Pejotização agrava problema e previdência perde contribuintes mais ricos. Disponível em: https://valdivinodesousa.jusbrasil.com.br/noticias/532769468/pejotizacao-agrava-problema-e-previdencia-perdecontribuintes-mais-ricos. Acesso em: 6 jul. 2019.

8 Rádio Câmara. Reforma Trabalhista: teletrabalho e autônomo exclusivo - Bloco 8. Disponível em: https://www2.camara.leg.br/camaranoticias/radio/materias/REPORTAGEM-ESPECIAL/561197-REFORMATRABALHISTA-TELETRABALHO-E-AUTONOMO-EXCLUSIVO-BLOCO-8.html. Acesso em: 6 jul. 2019.

Laborare. Ano II, Número 3, Jul-Dez/2019, pp. 81-105. ISSN 2595-847X. https://trabalhodigno.org/laborare DOI: https://doi.org/10.33637/2595-847x.2019-36 
Pejotização, como o próprio termo revela, refere-se ao processo de mascaramento e eliminação legal de relações de emprego, consolidando-se pela transformação do empregado em um prestador de serviços legalizado como pessoa jurídica. Trata-se, portanto, de eliminar o vínculo de emprego para reconhecer e estabelecer relações de trabalho com o agora trabalhador autônomo, então desprovido de direitos, proteções e garantias associadas ao assalariamento. $O$ processo de pejotização envolve uma série de elementos associados às transformações do trabalho observadas nas últimas décadas, em uma perspectiva global, entre eles: 1) as ameaças do desemprego e as consequentes pressões sobre o trabalhador, que minam as possibilidades de resistência; 2) a possibilidade de transferir para o trabalhador o próprio gerenciamento sobre seu trabalho, sem que isto signifique eliminar a relação de subordinação ou a perda de controle sobre o trabalho; 3) as pressões por desregulamentação da jornada de trabalho combinada com a crescente indistinção entre o que é e o que não é tempo de trabalho. Dessa forma, a transformação do trabalhador em pessoa jurídica atende a um dos elementos centrais da flexibilização do trabalho para as empresas, ao mesmo tempo em que significa uma eliminação de direitos, proteções e garantias ao trabalhador. Além disso, se, por um lado, a pejotização promove a perda de direitos, como horas extras remuneradas, intervalos e descanso remunerados, décimo terceiro salário, direitos e benefícios previdenciários, por outro, o não reconhecimento do vínculo empregatício e a transfiguração do trabalhador em uma empresa introduzem a possibilidade de sua sobrevivência ser inteiramente atrelada às demandas do capital, em uma espécie de remuneração baseada no "salário por peça" (nos termos contemporâneos, "por metas" ou "por produto"), tornando, assim, a força de trabalho utilizável de acordo com as exatas necessidades do contratante no setor privado e também público. Em outras palavras, o trabalhador é obrigado a gerir a vida como um negócio, em que todas as energias estarão voltadas para tornar-se comerciável.

O aparecimento do trabalhador autônomo exclusivo, promovido pela Reforma Trabalhista, pode levar ao entendimento equivocado de que ocorreu a legalização da pejotização, vindo a gerar um certo estímulo a esse mecanismo, ainda mais facilitado pela existência do Microempreendedor Individual (MEI) ${ }^{9}$.

9 Para ser um MEl, é necessário faturar até $\mathrm{R} \$ \mathbf{8 1 . 0 0 0 , 0 0}$ anuais, não ter participação em outra empresa como sócio ou titular e não possuir mais que um empregado contratado, que receba salário mínimo ou o piso da categoria. $O$ custo mensal fixo varia conforme a atividade econômica exercida e é de, no máximo, $R \$ 55,90$. $O$ cadastrado tem direito a salário-maternidade, auxílio-doença, aposentadoria, pensão por morte, isenção de tributos federais (Imposto de Renda, PIS, Cofins, IPI e CSLL), inscrição online no Cadastro Nacional de Pessoas Jurídicas (CNPJ) e emissão de nota fiscal. Fonte: Portal do Empreendedor. Como eu faço para abrir um Microempreendedor Individual - MEI? Disponível em: https://www.portaldoempreendedor.gov.br/duvidas-mais-

Laborare. Ano II, Número 3, Jul-Dez/2019, pp. 81-105. ISSN 2595-847X. https://trabalhodigno.org/laborare DOI: https://doi.org/10.33637/2595-847x.2019-36 
O artigo 442-B da CLT possibilita o escamoteamento de relações empregatícias, exprime Barros Filho (2019, p. 217), pois afasta a configuração do vínculo, privilegiando a forma (contrato de autônomo) em detrimento da realidade fática. Um dos momentos de maior vulnerabilidade do obreiro seria na fase de contratação, quando, pela necessidade de obter renda, a sua ação volitiva seria afetada, favorecendo essa dissimulação.

Segundo Galvão et al. (2017, p. 39-40), tal disposição visa a restringir o conceito de empregado, excluindo grande parcela da classe trabalhadora das garantias do direito trabalhista, inclusive as que dizem respeito à saúde e segurança no trabalho, ao viabilizar que qualquer trabalhador seja um autônomo, independentemente de sua dedicação e assiduidade. Com isso, os alicerces do vínculo empregatício seriam eliminados, podendo fazer o empregador refletir por que registraria um trabalhador sendo possível contratá-lo como autônomo.

A Reforma ensejaria uma desestruturação do mercado de trabalho formal, pois os trabalhadores, obrigados a serem pessoas jurídicas, ainda que com assiduidade e exclusividade para a mesma empresa, não poderiam mais reclamar os seus direitos na justiça trabalhista. Pior, trabalhadores contratados como empregados teriam diante de si um horizonte de demissões e de sua transmutação em trabalhadores autônomos.

A regulação do trabalho autônomo geraria uma contradição com o discurso do próprio governo de que a Reforma da Previdência é imperativa, tendo em vista que a ampla utilização do trabalho autônomo provocaria diminuição na arrecadação das contribuições previdenciárias.

Barros Filho (2019, p. 218) denota que a pejotização: “[...] provoca impacto na Previdência Social, com a redução de contribuições patronal e obreira que seriam devidas em decorrência de relações de emprego, as quais, pela dissimulação como contratação de mão de obra autônoma, passam a ser substituídas pela contribuição apenas do obreiro, reduzindo receita previdenciária".

Os números do Instituto Nacional do Seguro Social (INSS) demonstram que o grupo de contribuintes assalariados de renda mais elevada está reduzindo. De 1996 a 2015, o contingente dos que recebem acima de sete salários mínimos recuou 14\%. Já em faixa de renda superior, a dos que ganham mais de quinze salários mínimos, a queda foi de $33 \%$, revelando uma fatia menor de pessoas que pagam contribuições altas em um sistema

sobre-o-mei/as-duvidas-mais-frequentes-sobre-o-microemprendedor-individual/2-como-eu-faco-para-abrir-ummicroempreendedor-individual-mei. Acesso em: 14 jul. 2019. 
cujas despesas crescem mais que as receitas. Enquanto isso, de 2009 a 2015, o total de contribuintes não empregados cresceu mais do que o de contribuintes empregados ${ }^{10}$.

Para cada trabalhador que sai de um emprego com CTPS assinada e passa do Regime Geral da Previdência Social (RGPS) para o Simples Nacional/MEI, a Previdência Social deixa de arrecadar, em média, R\$ 3.661,71 anualmente. Considerando que esse movimento ocorre com $1 \%$ da força de trabalho celetista do setor privado, a perda de arrecadação é da ordem de R\$ 1,5 bilhão por ano (WELLE et al., 2018, p. 295).

\section{O TRABALHO AUTÔNOMO EXCLUSIVO SOB A ÓTICA DO DIREITO DO TRABALHO}

A Reforma Trabalhista inseriu o artigo 442-B na CLT, engendrando o trabalhador autônomo exclusivo. Diz o texto legal: "A contratação do autônomo, cumpridas por este todas as formalidades legais, com ou sem exclusividade, de forma contínua ou não, afasta a qualidade de empregado prevista no art. $3^{\circ}$. desta Consolidação" (original sem grifo).

Não foi desta vez que o legislador cuidou de delinear o trabalho autônomo ou de explicitar as formalidades genéricas inerentes à sua contratação. No tocante a isso, existem apenas regras esparsas em alguns diplomas legais, a exemplo do Código Civil $^{11}$, da Lei Federal $n^{\circ}$. 8.212/1991 ${ }^{12}$ e das leis que regem as profissões de corretor de imóveis e de corretor de seguros.

Nada obstante, é cediço que o trabalhador autônomo labora por conta própria, e não alheia, assumindo os riscos do negócio. Desenvolve a sua atividade de maneira discricionária, escolhendo o lugar, modo e tempo de sua execução, com organização e iniciativa próprias. É profissional independente, detém as ferramentas de trabalho, não está submetido ou subordinado a um empregador, não recebe ordens, não cumpre jornada, tampouco tem o seu trabalho gerenciado ou controlado, podendo, ainda, substituir a si mesmo por outrem.

A possibilidade de o trabalho autônomo ser prestado com exclusividade e continuidade é controversa, posto que, conquanto não caracterizem, isoladamente, o

10 Sousa, Valdivino. Pejotização agrava problema e previdência perde contribuintes mais ricos. Disponível em: https://valdivinodesousa.jusbrasil.com.br/noticias/532769468/pejotizacao-agravaproblema-e-previdencia-perde-contribuintes-mais-ricos. Acesso em: 6 jul. 2019.

11 Lei Federal no. 10.406, de 10 de janeiro de 2002.

12 Art. 12: "São segurados obrigatórios da Previdência Social as seguintes pessoas físicas: (...) V - como contribuinte individual: (...) h) a pessoa física que exerce, por conta própria, atividade econômica de natureza urbana, com fins lucrativos ou não (Incluído pela Lei no. 9.876, de 1999)". 


\section{Diego Pinto de Barros Leal}

vínculo de emprego, são indícios de trabalho subordinado por conta alheia, por ser a exclusividade confundível com a dependência econômica do trabalhador para com o tomador de seus serviços e a continuidade muito semelhante a não eventualidade do empregado, da qual é presumida a subordinação havendo a inserção deste em atividade empreendedora alheia.

Aliás, uma releitura do conceito de subordinação (consequência) é proposta por Sales (2019, p. 58-59) a partir da dependência (causa) do trabalhador, compreendido como aquele que depende, jurídica e economicamente, da venda de sua força de trabalho a outrem em troca de um valor (trabalho assalariado), o que explicaria, de forma mais apropriada, a situação dos altos empregados, os quais não são inseridos, mas determinam a inserção.

Contudo, em juízo diverso, Martins (2018, p. 33, apud MELO, 2019, p. 78) dispõe que a utilização do termo "dependência" como requisito do liame de emprego não seria adequada, preferindo a este o vocábulo "subordinação". E exemplifica a sua assertiva: "[...] o filho pode ser dependente do pai, mas não é a ele subordinado. A denominação mais correta é, portanto, subordinação. É também a palavra mais aceita na doutrina e na jurisprudência".

Noemia Garcia Porto, da Associação Nacional dos Magistrados da Justiça do Trabalho - ANAMATRA, critica a possibilidade de o autônomo ser exclusivo e avisa que a novidade é bastante polêmica, dando margem à contratação de profissional sem direitos básicos, tais como férias, gratificação natalina e fundo de garantia do tempo de serviço ${ }^{13}$. De acordo com ela, seria uma contradição conceitual, pois, com a exclusividade, o autônomo perderia a autonomia.

O paradigma agora parece ter sido invertido. Se antes os operadores do direito entendiam que era empregado o trabalhador que prestasse serviços para uma única empresa, agora a ratio legis indica, desde que cumpridas as formalidades legais, não prosperar a caracterização do liame de emprego fundada simplesmente na exclusividade e continuidade do trabalho, o que não impede que, conjugadas com mais elementos, sirvam a esse desígnio, notadamente quando também apuradas a pessoalidade e a subordinação. Haverá uma espécie de inversão do ônus da prova, em que será papel do trabalhador evidenciar que era subordinado ao contratante.

13 Sousa, Valdivino. Pejotização agrava problema e previdência perde contribuintes mais ricos. Disponível em: <https://valdivinodesousa.jusbrasil.com.br/noticias/532769468/pejotizacao-agrava-problema-e-previdencia-perdecontribuintes-mais-ricos $>$. Acesso em: 6 jul. 2019.

Laborare. Ano II, Número 3, Jul-Dez/2019, pp. 81-105. ISSN 2595-847X. https://trabalhodigno.org/laborare DOI: https://doi.org/10.33637/2595-847x.2019-36 
Filgueiras, Bispo e Coutinho (2018, p. 129) sustentam que "a intenção da nova redação do artigo 442 é, evidentemente, proteger, de eventuais repercussões concernentes ao direito do trabalho, as empresas que gerem sua força de trabalho sem admitir sua posição de empregadoras". Pretenderia a norma em tela rechaçar o regime de emprego mediante singela formalização de contrato de trabalho autônomo, desprezando prova em contrário, o que seria uma violação aos direitos fundamentais dos trabalhadores, expressos na relação de emprego, e um incentivo deliberado à fraude.

$\mathrm{Na}$ prática, os serviços seriam prestados de igual modo pelo trabalhador, mas custando bem menos ao empregador. Seriam factíveis a inobservância das regras de segurança e saúde no trabalho, o cumprimento pelo obreiro de jornadas laborais ampliadas, graças à desnecessidade de marcação de horários de entrada e saída, o pagamento de remuneração inferior ao salário mínimo, entre outros abusos às garantias constitucionais definidas no artigo $7^{\circ}$ da Carta Magna de 1988.

Nesse diapasão, a Recomendação 198 da Organização Internacional do Trabalho OIT, citada por Severo e Souto Maior (2017, p. 43), preconiza que: “[...] as políticas nacionais devem 'estabelecer efetivamente a existência de uma relação de trabalho e a distinção entre empregador e trabalhador autônomo', 'combater as relações de trabalho disfarçadas', evitando 'acordos contratuais que possuam o efeito de privar trabalhadores de sua devida proteção"”.

O novo ditame deve ser interpretado consoante os princípios do não retrocesso, da busca do pleno emprego e da primazia da realidade. Sempre que houver fraude à configuração do emprego, a prescrição do artigo $9^{\circ}$ da CLT será atraída: "Serão nulos de pleno direito os atos praticados com o objetivo de desvirtuar, impedir ou fraudar a aplicação dos preceitos contidos na presente Consolidação" (original sem grifo).

Os contratos que, embora tenham como objeto a prestação de serviços, só sejam destinados a fornecer mão de obra podem constituir desvirtuamento do trabalho autônomo. Na percepção de Oliveira (2014, p. 217-218, apud SALES, 2019, p. 61), o trabalho assalariado é contrato de compra e venda de força de trabalho. O trabalho dissociado da propriedade não poderia agir como empresa.

Na opinião de Sales (2019, p. 68), as circunstâncias da contratação do trabalhador devem ser investigadas. É empregado o obreiro que, precipuamente pelo seu trabalho, não vê outra opção a não ser subsumir a si mesmo em propriedade alheia em troca de uma contraprestação pecuniária. $\mathrm{O}$ autônomo, diferentemente, antes de ser 
contratado, possui estrutura pronta e junge o seu negócio ao de terceiro contratante em benefício mútuo.

A redação do artigo 442-B possui semelhança com o artigo 442, parágrafo único, da CLT, incluso pela Lei Federal no $n^{\circ}$ 8.949, de 9 de dezembro de 1994, cujo teor refuta, qualquer que seja o ramo de atividade da sociedade cooperativa, a existência de liame empregatício entre ela e seus associados e entre estes e os tomadores de serviços daquela. Prova disso é o ex-Deputado Rogério Marinho, na página 47 de seu relatório para votação do Projeto de Lei $n^{\circ} .6 .787 / 2016^{14}$, asseverar que:

$\mathrm{O}$ art. 442-B, inserido na CLT nesta oportunidade, segue o mesmo raciocínio adotado em relação à descaracterização do vínculo empregatício entre a sociedade cooperativa e o seu associado. De fato, não há motivo razoável para configurar vínculo empregatício entre a empresa e um autônomo que lhe preste algum serviço eventual. Ressalte-se que, na eventualidade de uma tentativa de se fraudar a legislação trabalhista, estando configurados os requisitos próprios da relação de emprego, a Justiça do Trabalho poderá reconhecer o vínculo empregatício, garantindo ao empregado todos os direitos a ele inerentes.

Em ambos os casos, seja de autônomo exclusivo, seja de cooperativado, o importante a analisar não são os aspectos formais da relação pactuada entre os celebrantes, e sim os aspectos materiais, o "contrato-realidade", justamente por deferência ao princípio da primazia da realidade, basilar no direito do trabalho, que acaba relativizando o comando de afastamento de vínculo empregatício, consignado, talvez, sem maiores cuidados. A regra recente é até mais instável, haja vista que autonomia ou subordinação não é imposta por lei (SEVERO; SOUTO MAIOR, 2017, p. 39).

Por ocasião da Segunda Jornada de Direito Material e Processual do Trabalho, evento que contou com a participação de juízes, auditores-fiscais, procuradores, juristas e advogados trabalhistas, a ANAMATRA divulgou, em 19 de outubro de 2017, cento e

\footnotetext{
14 Câmara dos Deputados. Parecer ao Projeto de Lei no. 6.787, de 2016, do Poder Executivo, que "altera o Decreto-lei nㅇ. 5.452, de 10 de maio de 1943 - Consolidação das Leis do Trabalho, e a Lei no. 6.019, de 3 de janeiro de 1974, para dispor sobre eleições de representantes dos trabalhadores no local de trabalho e sobre trabalho temporário, e dá outras providências", também denominada de "Reforma Trabalhista". Disponível em: <http://www.camara.gov.br/proposicoesWeb/prop mostrarintegra? codteor $=1548298 \&$ filename $=$ SBT $+2+$ PL678716+\%3D \%3E + PL $+6787 / 2016>$. Acesso em: 6 jul. 2019.
} 
vinte e cinco enunciados referentes à interpretação e aplicação da Reforma ${ }^{15}$, dos quais quatro estão diretamente ligados ao trabalho autônomo exclusivo ${ }^{16}$, conforme a seguir:

51 - TRABALHADOR AUTÔNOMO EXCLUSIVO E ART. $9^{\circ}$ DA CLT

TRABALHADOR AUTÔNOMO EXCLUSIVO. RECONHECIMENTO DA RELAÇÃO DE EMPREGO. A NORMA DO ARTIGO 442-B DA CLT NÃO IMPEDE O RECONHECIMENTO DA RELAÇÃO DE EMPREGO, QUANDO PRESENTES OS PRESSUPOSTOS DOS ARTIGOS $2^{\circ}$ E $3^{\circ}$ DA CLT E CONFIGURADO O DESVIRTUAMENTO DO TRABALHO AUTÔNOMO, COM FRAUDE À RELAÇÃO DE EMPREGO, À LUZ DO ART. $9^{\circ}$ DA CLT.

52 - TRABALHADOR AUTÔNOMO EXCLUSIVO E PRIMAZIA DA REALIDADE

PRIMAZIA DA REALIDADE SOBRE A FORMA. É A PRIMAZIA DA REALIDADE, E NÃO A FORMALIDADE EXTERIORIZADA DE ATOS E NEGÓCIOS JURÍDICOS, QUE DEVE SER CONSIDERADA PARA O RECONHECIMENTO DO VÍNCULO DE EMPREGO (ARTS. $2^{\circ}$ E $3^{\circ}$ DA CLT) OU DE TRABALHO AUTÔNOMO (ART. 442-B DA CLT).

53 - TRABALHO AUTÔNOMO CONTÍNUO E EXCLUSIVO. LIMITES E INTERPRETAÇÃO CONFORME: INTELIGÊNCIA DO ART. 442-B DA CLT À LUZ DA CONSTITUIÇÃO FEDERAL.

PRESUME-SE O VÍNCULO EMPREGATÍCIO DIANTE DA PRESTAÇÃO DE SERVIÇOS CONTÍNUA E EXCLUSIVA, UMA VEZ QUE A RELAÇÃO DE EMPREGO É DIREITO FUNDAMENTAL (ARTS. $1^{\circ}$, III E IV, $5^{\circ}$, CAPUT, E $7^{\circ}$ DA CF/1988), DEVENDO O ART. 442-B DA CLT SER INTERPRETADO CONFORME A CONSTITUIÇÃO FEDERAL PARA AFASTAR A CARACTERIZAÇÃO DO TRABALHO AUTÔNOMO SEMPRE QUE O TRABALHADOR, NÃO ORGANIZANDO A PRÓPRIA ATIVIDADE, TENHA SEU LABOR UTILIZADO NA ESTRUTURA DO EMPREENDIMENTO E INTEGRADO À SUA DINÂMICA.

15 Associação Nacional dos Magistrados da Justiça do Trabalho - ANAMATRA. Reforma trabalhista: Anamatra divulga íntegra dos enunciados aprovados na $2 \underline{a}$ Jornada. Disponível em: https://www.anamatra.org.br/imprensa/noticias/25797-reforma-trabalhista-anamatra-divulga-integra-dosenunciados-aprovados-na-2-jornada. Acesso em: 6 jul. 2019. 16 2․ Jornada de Direito Material e Processual do Trabalho. Enunciados Aprovados na 2a Jornada. Disponível em: 〈http://www.jornadanacional.com.br/listagem-enunciados-aprovados-vis1.asp >. Acesso em: 6 jul. 2019. 


\section{4 - TRABALHADOR AUTÔNOMO EXCLUSIVO E FORMAS JURÍDICAS IRREAIS}

O ARTIGO 442-B DA CLT NÃO PERMITE A CONTRATAÇÃO DE TRABALHADOR CONSTITUÍDO SOB A FORMA DE PESSOA JURÍDICA, DE MICROEMPREENDEDOR INDIVIDUAL (MEI) E DE EMPRESA INDIVIDUAL DE RESPONSABILIDADE LIMITADA (EIRELI), ENTRE OUTRAS, QUANDO PRESENTES OS PRESSUPOSTOS PARA O RECONHECIMENTO DA RELAÇÃO DE EMPREGO (ARTS. $2^{\circ}$ E $3^{\circ}$ DA CLT).

Seguindo uma linha de interpretação sistemática e teleológica do artigo 442-B da CLT, os enunciados transcritos conduzem, outra vez, à imperiosa conclusão de que são os elementos fático-jurídicos do caso concreto que determinarão a existência ou não de laço empregatício, pouco importando o invólucro formal conferido ao contrato ajustado entre as partes.

É dizer, se o contratado como autônomo cumprir o contrato preenchendo os requisitos da relação de emprego, será considerado empregado do tomador de serviços. Faltando, porém, pelo menos um deles, a relação entre as partes não será de emprego (DELGADO; DELGADO, 2017, p. 152-153).

Os requisitos do liame empregatício, que não passaram por quaisquer mutações, são os dispostos nos artigos $2^{\circ}$, caput, e $3^{\circ}$, caput, da CLT, os quais definem, respectivamente, os conceitos de empregador e empregado. Portanto, continuam sendo pessoalidade, trabalho por pessoa física, não eventualidade, onerosidade e subordinação.

Particularmente, o Enunciado 53 prescreve que é presumido o vínculo de emprego diante de prestação de serviços contínua e exclusiva, afastando a caracterização do trabalho autônomo, sempre que o trabalhador, não organizando a própria atividade, tenha o seu labor utilizado na estrutura do empreendimento e integrado à sua dinâmica.

A ideia proposta está alinhada com uma visão evoluída de subordinação, difundida em tempos recentes e bem aceita no meio juslaboral, objetivando, de modo a acompanhar a reestruturação produtiva e o avanço da tecnologia, transpor a subordinação em sua concepção clássica, em que o empregado estava sujeito a receber ordens resultantes do poder diretivo do empregador, que fiscalizava, gerenciava e controlava o trabalho daquele. 
Muitas relações de trabalho podem suscitar dúvidas quanto à existência de autonomia ou de subordinação. No intuito de superar essa dificuldade, o critério estrutural de subordinação, defendido por Delgado (2016, p. 314-315), é verificado quando o trabalhador está dentro da dinâmica do tomador de seus serviços, dele recebendo ou não ordens diretas, seguindo, como parte de um todo, a organização e cultura do empreendimento para o qual presta serviços.

Já para Porto (2009, p. 253), a subordinação, em sua dimensão integrativa, deve ser esmiuçada:

[...] quando a prestação do trabalho integra as atividades exercidas pelo empregador e o trabalhador não possui uma organização empresarial própria, não assume verdadeiramente os riscos de perdas ou ganhos e não é proprietário dos frutos do seu trabalho, que pertencem, originariamente, à organização produtiva alheia para a qual presta a sua atividade.

Por falar nisso, o artigo $6^{\circ}$ da CLT, atualizado em 2011, está calhado nesse enredo:

Art. $6^{\circ}$. Não se distingue entre o trabalho realizado no estabelecimento do empregador, o executado no domić́lio do empregado e o realizado a distância, desde que estejam caracterizados os pressupostos da relação de emprego.

Parágrafo único. Os meios telemáticos e informatizados de comando, controle e supervisão se equiparam, para fins de subordinação jurídica, aos meios pessoais e diretos de comando, controle e supervisão do trabalho alheio.

A subordinação, em sua multidimensionalidade, é melhor elucidada por Silva (2015, p. 21-22) nos seguintes termos:

É importante notar que alguns graus de submetimento de uma parte em relação à outra existem em todas as relações civis e comerciais, não se tratando de uma exclusividade do direito do trabalho. O que diferencia a subordinação jurídica trabalhista das demais formas de subordinação é exatamente sua dimensão, a que chamaremos de grau de subordinação.

Propõe-se que, para definir a relação de emprego, seja utilizada a expressão subordinação em grau máximo ou em grau maior, ao passo que as formas de trabalho autônomo se mostram dotadas de subordinação em 
grau médio, e algumas formas de contratos civis mais fugazes se revestem de subordinação em grau mínimo.

$[\ldots]$

Se fôssemos representar a subordinação geometricamente, teríamos círculos concêntricos: o núcleo duro desses círculos seria a subordinação mais intensa, própria do contrato de trabalho, a partir do qual surgiriam outros círculos com maior quantidade de pessoas incluídas, mas menor intensidade de subordinação, até o desaparecimento completo da subordinação, de acordo com a natureza jurídica do contrato em questão. A propósito, é comum se ver o uso do neologismo "parassubordinação" para se identificar esse grupo de trabalhadores no segundo ou no máximo no terceiro círculo, assim entendidos aqueles que, conquanto não tenham sido considerados empregados pelos ditames da legislação social, guardam com eles os mesmos aspectos de vulnerabilidade, de necessidade do trabalho como fonte de subsistência e características como a habitualidade na prestação dos serviços e a pessoalidade em sua apresentação.

Alex Myller, Auditor-Fiscal do Trabalho, entende que é forçoso analisar as relações de trabalho no plano fático para detectar eventuais indícios de subordinação. A fiscalização trabalhista constata primeiro se o trabalhador é subordinado; se for, mesmo que lhe seja dada a aparência de autônomo, a relação será considerada de emprego. Todavia, sendo realmente autônomo, o legislador intentou, nesse caso, autorizar o trabalhador a prestar serviços para apenas uma empresa, o que já seria um sinal de que ele não é tão autônomo.

Alexandre Agra Belmonte, Ministro do Tribunal Superior do Trabalho, também acredita ser a subordinação o requisito que definirá a existência de vínculo de emprego, já que o autônomo, por ser senhor de si mesmo, dita as regras do serviço que executará e pode recusar a realização de uma atividade demandada pelo contratante, ao passo que o empregado não.

Quando existente a exclusividade, prossegue, será fundamental vasculhar se ela foi ou não imposta pelo tomador do serviço. Caso ocorra por conta do trabalhador, não haverá problema, porquanto o contrato tradicional de emprego não é o único que oferece garantias ao trabalhador. Do contrário, haverá uma fraude, cujo deslinde será 
o reconhecimento de vínculo empregatício em prol do obreiro e aplicação de penalidade ao tomador do serviço ${ }^{17}$.

Em tese, um trabalhador autônomo pode, espontaneamente, prestar serviços a um único tomador por lhe ser mais viável financeiramente ou o serviço requerer tempo suficiente a ponto de não conseguir trabalhar para outros contratantes. Contudo, sendo a exclusividade do prestador uma condição exigida pelo tomador de serviços, a situação será outra, bem próxima ao laço de emprego (FONSECA, 2018, p. 41).

Aponta Barros Filho (2019, pp. 217-218) que, celebrado o contrato com um trabalhador dito autônomo, as peculiaridades da execução contratual e o animus (ação volitiva) dos celebrantes mostrarão a coerência ou não do pacto com a realidade fática. Logo, quando presente a subordinação, traço diferencial entre o trabalho autônomo e a relação de emprego, será materializada a qualidade de empregado do trabalhador.

Levando isso em conta, a Medida Provisória $\mathrm{n}^{\mathrm{o}}$. 808/2017, vigente de 14 de novembro de 2017 a 23 de abril de 2018, retirou o termo "com ou sem exclusividade" do caput do artigo 442-B da CLT e adicionou, no $\S 1^{\circ}$, restrição à celebração de cláusula de exclusividade na contratação de trabalhador autônomo, esclarecendo, no $\S$ $2^{\circ}$, que a prestação exclusiva de serviços a um tomador de serviços não descaracteriza o trabalho autônomo.

Cláusula de exclusividade tem a ver com o contrato e, por isso, não pode ser confundida com prestação exclusiva, relativa ao plano fático, isto é, a prestação de serviços a apenas um tomador não deslegitima o trabalho autônomo, sendo garantido a este o direito de prestar serviços de qualquer natureza a outros tomadores que exerçam ou não a mesma atividade econômica (não exclusividade), sob qualquer modalidade de trabalho $\left(\S 3^{\circ}\right)$.

O trabalhador autônomo pode, já que desenvolve a sua atividade por conta própria, recusar a realização de atividade demandada pelo contratante, mesmo que, em decorrência disso, haja incidência de eventual penalidade assentada em cláusula contratual $\left(\S 4^{\circ}\right)$, e exercer qualquer atividade ligada ao negócio da empresa contratante, considerando a superação dos limites à terceirização $\left(\S 7^{\circ}\right)$.

17 Rádio Câmara. Reforma Trabalhista: teletrabalho e autônomo exclusivo - Bloco 8. Disponível em: https://www2.camara.leg.br/camaranoticias/radio/materias/REPORTAGEM-ESPECIAL/561197-REFORMATRABALHISTA-TELETRABALHO-E-AUTONOMO-EXCLUSIVO-BLOCO-8.html. Acesso em: 6 jul. 2019. 
Ademais, a aludida MP elencou certas categorias profissionais às quais conferiu, desde que atendidos os requisitos legais, a possibilidade de serem tidas como autônomas $\left(\S 5^{\circ}\right)$ e determinou, como não poderia deixar de ser, o reconhecimento do vínculo de emprego quando presente a subordinação jurídica $\left(\S 6^{\circ}\right)$. Eis um comparativo:

\section{REDAÇÃO DADA PELA LEI N ${ }^{\circ}$ 13.467/2017:}

Art. 442-B. A contratação do autônomo, cumpridas por este todas as formalidades legais, com ou sem exclusividade, de forma contínua ou não, afasta a qualidade de empregado prevista no art. $3^{\circ}$. desta Consolidação.

\section{REDAÇÃO DADA PELA MEDIDA PROVISÓRIA Nº. 808/2017:}

Art. 442-B. A contratação do autônomo, cumpridas por este todas as formalidades legais, de forma contínua ou não, afasta a qualidade de empregado prevista no art. $3^{\circ}$. desta Consolidação.

$\S 1^{\mathrm{o}}$. É vedada a celebração de cláusula de exclusividade no contrato previsto no caput.

$\S 2^{\circ}$. Não caracteriza a qualidade de empregado prevista no art. $3^{\circ}$. o fato de o autônomo prestar serviços a apenas um tomador de serviços.

$\S 3^{\circ}$. O autônomo poderá prestar serviços de qualquer natureza a outros tomadores de serviços que exerçam ou não a mesma atividade econômica, sob qualquer modalidade de contrato de trabalho, inclusive como autônomo.

$\S 4^{\circ}$. Fica garantida ao autônomo a possibilidade de recusa de realizar atividade demandada pelo contratante, garantida a aplicação de cláusula de penalidade prevista em contrato.

$\S 5^{\circ}$. Motoristas, representantes comerciais, corretores de imóveis, parceiros e trabalhadores de outras categorias profissionais reguladas por leis específicas relacionadas a atividades compatíveis com o contrato autônomo, desde que cumpridos os requisitos do caput, não possuirão a qualidade de empregado prevista no art. $3^{\circ}$. 
$\S 6^{\circ}$. Presente a subordinação jurídica, será reconhecido o vínculo empregatício.

$\S 7^{\circ}$. O disposto no caput se aplica ao autônomo, ainda que exerça atividade relacionada ao negócio da empresa contratante. (NR) (original com grifos).

Por seu turno, com a perda de eficácia da MP 808/2017 e o retorno à redação original do artigo 442-B da CLT, foi editada a Portaria MTb nº. 349/2018, que reproduziu, no caput de seu artigo $1^{\circ}$, o artigo celetista e, em cinco parágrafos, os $\S \S 2^{\circ}$ a $6^{\circ}$ da antiga medida provisória. In verbis:

(...) Art. $1^{\circ}$. A contratação do autônomo, cumpridas por este todas as formalidades legais, com ou sem exclusividade, de forma contínua ou não, afasta a qualidade de empregado prevista no art. $3^{\circ}$. do Decreto-Lei $n^{\circ}$. 5.452 , de $1^{\circ}$. de maio de 1943 , que aprova a Consolidação das Leis do Trabalho.

$\S 1^{\circ}$. Não caracteriza a qualidade de empregado prevista no art. $3^{\circ}$. da Consolidação das Leis do Trabalho o fato de o autônomo prestar serviços a apenas um tomador de serviços.

$\S 2^{\circ}$. O autônomo poderá prestar serviços de qualquer natureza a outros tomadores de serviços que exerçam ou não a mesma atividade econômica, sob qualquer modalidade de contrato de trabalho, inclusive como autônomo.

$\S 3^{\circ}$. Fica garantida ao autônomo a possibilidade de recusa de realizar atividade demandada pelo contratante, garantida a aplicação de cláusula de penalidade, caso prevista em contrato.

$\S 4^{\circ}$. Motoristas, representantes comerciais, corretores de imóveis, parceiros, e trabalhadores de outras categorias profissionais reguladas por leis específicas relacionadas a atividades compatíveis com o contrato autônomo, desde que cumpridos os requisitos do caput, não possuirão a qualidade de empregado prevista no art. $3^{\circ}$. da Consolidação das Leis do Trabalho.

$\S 5^{\circ}$. Presente a subordinação jurídica, será reconhecido o vínculo empregatício (...). 


\section{CONSIDERAÇÕES FINAIS}

$\mathrm{O}$ trabalho autônomo exclusivo, despontado no seio de um projeto de lei muito mais abrangente do que o original, enviado pelo Poder Executivo, tramitado de forma açodada no Congresso Nacional, por meio de articulações políticas duvidosas, sem a promoção de um profundo debate com os diversos setores interessados da sociedade em torno de suas modificações, em uma patente finalidade de acelerar a aprovação da Reforma Trabalhista, traz consigo algumas incertezas que haviam sido atenuadas com a edição de medida provisória.

Não à toa, o ex-Deputado Ronaldo Nogueira, então Ministro de Estado do Trabalho, ao longo do ano 2017, reconheceu publicamente, ainda como Presidente da Comissão de Trabalho, Administração e Serviço Público - CTASP da Câmara dos Deputados, no ano seguinte ao início da vigência da Reforma, que o regramento do trabalho autônomo exclusivo precisava ser aprimorado, acrescentando, ainda, que isso seria viabilizado pela comissão ${ }^{18}$.

Por sinal, a iniciativa legislativa voltada a acabar com a figura do trabalhador autônomo exclusivo tem sido, recentemente, observada no Parlamento. A Comissão de Direitos Humanos e Legislação Participativa - CDH do Senado Federal aprovou, em 23 de maio de 2019, a retirada da CLT de seu artigo 442-B. A proposta está registrada no Projeto de Lei do Senado - PLS n ${ }^{\circ}$. 270/2017 e segue para análise de outras comissões ${ }^{19}$.

Para o autor do projeto, Senador Paulo Paim, o dispositivo legal contraria o conceito de trabalhador autônomo, pois, não sendo subordinado ao tomador, o obreiro deveria ser livre para prestar serviços a quem quisesse. Além disso, esclarece que é preciso revogar a medida porque ela pode estimular contratações fraudulentas destinadas ao não recolhimento de encargos sociais. Já o relator do projeto, Senador Telmário Mota, sustenta que o artigo 442-B da CLT gera insegurança jurídica às relações trabalhistas, atrapalhando a vida dos empresários, o que não pode ser tolerado.

A despeito de a justificativa para a positivação dessa figura ter sido conferir maior segurança jurídica aos contratantes, o resultado obtido parece ter sido o inverso, na medida em que o artigo 442-B da CLT gera interpretação equivocada da parte de

18 Rádio Câmara. Reforma Trabalhista: teletrabalho e autônomo exclusivo - Bloco 8. Disponível em: https://www2.camara.leg.br/camaranoticias/radio/materias/REPORTAGEM-ESPECIAL/561197-REFORMATRABALHISTA-TELETRABALHO-E-AUTONOMO-EXCLUSIVO-BLOCO-8.html. Acesso em: 6 jul. 2019. 19 Agência Senado. Projeto aprovado na $\mathrm{CDH}$ acaba com figura do autônomo exclusivo. Disponível em: https://www12.senado.leg.br/noticias/materias/2019/05/23/projeto-aprovado-na-cdh-acaba-com-figura-doautonomo-exclusivo. Acesso em: 6 jul. 2019.

Laborare. Ano II, Número 3, Jul-Dez/2019, pp. 81-105. ISSN 2595-847X. https:/trabalhodigno.org/laborare DOI: https://doi.org/10.33637/2595-847x.2019-36 
alguns atores sociais e dá margem à proliferação desmedida de empregados travestidos de pessoas jurídicas, a chamada pejotização, prejudicando a classe trabalhadora no que tange à efetivação de seus direitos assegurados constitucionalmente e impactando negativamente as contas já tão combalidas da Previdência Social.

Em linhas gerais, o trabalhador autônomo labora por conta própria, assume os riscos do negócio, detém as ferramentas de trabalho, não está sujeito a gerenciamento ou controle de seu trabalho e pode substituir a si mesmo por outrem. Por essas razões, o fato de ele poder prestar serviços com exclusividade e continuidade a um tomador e não perder essa qualidade tem de ser corretamente contextualizado.

O tomador de serviços não pode impor ao contratado a exclusividade, que deve ser uma escolha espontânea deste. Quer dizer, a exclusividade é uma opção, e não uma imposição. Ademais, o autônomo pode recusar a realização de atividade demandada pelo contratante. Tanto assim que a MP $\mathrm{n}^{\circ}$. 808/2017 vedou o estabelecimento de cláusula de exclusividade na contratação do trabalhador, além de ter permitido a aplicação de penalidade em caso de ele recusar atividade que lhe for solicitada.

Essa forma de prestação de serviços não transparece, invariavelmente, a existência de um liame empregatício, tendo em vista que o trabalhador pode avaliar que lhe é mais vantajosa financeiramente a exclusividade ou que o serviço demanda tanto tempo que não consiga trabalhar para outros contratantes, hipóteses que, na prática, estão restritas a situações específicas, a exemplo do que ocorre com determinados motoristas, representantes comerciais e corretores de imóveis.

Nessa circunstância, a continuidade parece ser decorrência lógica da exclusividade e com ela estar intimamente conectada. Ora, se o trabalhador autônomo presta serviços exclusivos a um tomador, é natural que tais serviços sejam contínuos, do contrário não lhe sobraria outra fonte de renda. A continuidade dos serviços pressupõe a sua constância ao longo do tempo, sem traduzir uma maior ou menor frequência com que os serviços são prestados.

O ponto fulcral para diferenciar o trabalho autônomo da relação de emprego é a subordinação. Ainda que o trabalhador tenha, de livre vontade, optado por prestar serviços exclusivos a um tomador, exercendo este algum tipo de ingerência sobre o obreiro, segundo tese vanguardista de conceituada parcela da doutrina, certamente a relação travada será de emprego caso sejam confirmados os demais requisitos que the são inerentes. 


\section{Diego Pinto de Barros Leal}

No direito do trabalho, um dos princípios fundamentais a serem considerados é o da primazia da realidade, o qual, aliado aos princípios do não retrocesso e da busca do pleno emprego, deve orientar a análise da situação concreta, a fim de determinar a existência ou não do vínculo empregatício, que, uma vez verificado, prepondera mesmo em face de uma fraude perpetrada por meio de dissimulação contratual, com espeque no artigo $9^{\circ}$ da CLT.

Malogra o multicitado artigo justamente por não explicitar a integralidade dessas observações em seu bojo e relegar algumas delas a um instrumento infralegal na exata proporção daquilo que não lhe é adverso. Entretanto, não pode o desígnio do legislador ser compreendido como uma legalização da pejotização, e sim como uma tentativa de conferir maior segurança jurídica aos contratantes, inobstante tenha utilizado, para tanto, técnica redacional imperfeita.

\section{REFERÊNCIAS}

Agência Senado. (2018). Medida Provisória que altera reforma trabalhista perde a validade nesta segunda. Disponível em: https://www12.senado.leg.br/noticias/materias/2018/04/20/medida-provisoria-quealtera-reforma-trabalhista-perde-a-validade-nesta-segunda. Acesso em: 14 jul. 2019.

Agência Senado. (2019). Projeto aprovado na CDH acaba com figura do autônomo exclusivo. Disponível em: https://www12.senado.leg.br/noticias/materias/2019/05/23/ projeto-aprovado-na-cdh-acaba-com-figura-do-autonomo-exclusivo. Acesso em: 6 jul. 2019.

Associação Nacional dos Magistrados da Justiça do Trabalho - ANAMATRA. (2017). Reforma trabalhista: Anamatra divulga íntegra dos enunciados aprovados na $2^{\mathrm{a}}$ Jornada. Disponível em: https://www.anamatra.org.br/imprensa/noticias/25797reforma-trabalhista-anamatra-divulga-integra-dos-enunciados-aprovados-na-2jornada. Acesso em: 6 jul. 2019.

Barros Filho, Celso de. (2019). Reforma Trabalhista: Aumenta o Déficit Público e Contradiz a Necessidade de Reforma da Previdência. In: Silva Filho, Carlos Fernando da; Jorge, Rosa Maria Campos; Rassy, Rosângela Silva (org.). Reforma Trabalhista: uma reflexão dos Auditores-Fiscais do Trabalho sobre os efeitos da Lei n. 13.467/2017 para os trabalhadores. São Paulo: Ltr, p. 215-226.

Brasil. Constituição da República Federativa do Brasil, de 5 de outubro de 1988. Disponível em: $<$ http://www.planalto.gov.br/ccivil 03/constituicao/constituicaocompilado.htm>. Acesso em: 16 jul. 2019. 
Brasil. Decreto-Lei $n^{\circ}$. 5.452, de $1^{\circ}$ de maio de 1943. Aprova a Consolidação das Leis do Trabalho. Disponível em: $<$ http://www.planalto.gov.br/ccivil_03/decreto-lei/del5452.htm>. Acesso em: 13 jul. 2019.

Brasil. Exposição de Motivos $n^{o}$. 00023/2017 do Ministro de Estado do Trabalho. Disponível $<$ http://www.planalto.gov.br/ccivil_03/_Ato2015-2018/2017/Mpv/mpv808.htm>. Acesso em: 7 jul. 2019.

Brasil. Lei Federal no . 8.212, de 24 de julho de 1991. Dispõe sobre a organização da Seguridade Social, institui Plano de Custeio e dá outras providências. Disponível em: $<$ http://www.planalto.gov.br/ccivil 03/leis/L8212cons.htm>. Acesso em: 20 jul. 2019.

Brasil. Lei Federal no . 8.949, de 9 de dezembro de 1994. Acrescenta parágrafo ao art. 442 da Consolidação das Leis do Trabalho (CLT) para declarar a inexistência de vínculo empregatício entre as cooperativas e seus associados. Disponível em: $<$ http:// www.planalto.gov.br/ccivil 03/LEIS/L8949.htm>. Acesso em: 16 jul. 2019.

Brasil. Lei Federal $n^{\circ}$. 13.467, de 13 de julho de 2017. Altera a Consolidação das Leis do Trabalho (CLT), aprovada pelo Decreto-Lei $n^{\circ}$. 5.452, de $1^{\circ}$. de maio de 1943, e as Leis Federais $\mathrm{n}^{\circ}$. 6.019, de 3 de janeiro de 1974, $\mathrm{n}^{\circ} .8 .036$, de 11 de maio de 1990, e $\mathrm{n}^{\circ} .8 .212$, de 24 de julho de 1991, a fim de adequar a legislação às novas relações de trabalho. Disponível em: $<$ http://www.planalto.gov.br/ccivil 03/ ato2015-2018/2017/lei/113467.htm>. Acesso em: 6 jul. 2019.

Brasil. Medida Provisória $n^{\circ}$. 808, de 14 de novembro de 2017. Altera a Consolidação das Leis do Trabalho - CLT, aprovada pelo Decreto-Lei ${ }^{\circ}$. 5.452, de $1^{\circ}$. de maio de $1943 . \quad$ Disponível em: $<$ http://www.planalto.gov.br/ccivil 03/ Ato2015-2018/2017/Mpv/mpv808.htm $>$.

Acesso em: 7 jul. 2019.

Brasil. Portaria do Ministro de Estado do Trabalho $n^{\circ}$. 349, de 23 de maio de 2018. Estabelece regras voltadas à execução da Lei Federal $n^{\circ}$. 13.467, de 13 de julho de 2017, no âmbito das competências normativas do Ministério do Trabalho. Disponível em: $<$ http://pesquisa.in.gov.br/imprensa/jsp/visualiza/index.jsp? $\underline{\text { data }=24 / 05 / 2018 \& \text { jornal }=515 \& \text { pagina }=92}>$. Acesso em: 6 jul. 2019.

Câmara dos Deputados. Parecer ao Projeto de Lei $n^{\circ}$. 6.787, de 2016, do Poder Executivo, que "altera o Decreto-lei $\mathrm{n}^{\circ} .5 .452$, de $1^{\circ}$. de maio de 1943 - Consolidação das Leis do Trabalho, e a Lei $\mathrm{n}^{\circ}$. 6.019, de 3 de janeiro de 1974, para dispor sobre eleições de representantes dos trabalhadores no local de trabalho e sobre trabalho 


\section{Diego Pinto de Barros Leal}

temporário, e dá outras providências", também denominada de "Reforma Trabalhista". Disponível em:

$<$ http://www.camara.gov.br/proposicoesWeb/prop mostrarintegra? codteor $=1548298 \&$ filename $=\mathrm{SBT}+2+\mathrm{PL} 678716+\% 3 \mathrm{D} \% 3 \mathrm{E}+\mathrm{PL}+6787 / 2016>$. Acesso em: 6 jul. 2019.

Delgado, Maurício Godinho. (2016). Curso de direito do trabalho. 15. ed. São Paulo: LTr, p. 314-315.

Delgado, Maurício Godinho; Delgado, Gabriela Neves. (2017). A Reforma Trabalhista no Brasil: Com os Comentários à Lei n. 13.467/2017. São Paulo: LTr, p. 152-153.

Filgueiras, Vitor; Bispo, Bruna; Coutinho, Pablo. (2018). A reforma trabalhista como reforço a tendências recentes no mercado de trabalho. In: Krein, José Dari; Gimenez, Denis Maracci; Santos, Anselmo Luis dos (org.). Dimensões Críticas da Reforma Trabalhista no Brasil. Campinas: Curt Nimuendajú, p. 129.

Fonseca, Rodrigo Dias da et al. (2018). Reforma Trabalhista Comentada MP 808/2017: Análise de todos os artigos. Florianópolis: Empório do Direito, 2018.

Galvão, Andréia et al. (2017). Dossiê Reforma Trabalhista. In: Teixeira, Marilane Oliveira et al. (org.). Contribuição Crítica à Reforma Trabalhista. Campinas: CESIT/ IE/UNICAMP, p. 39-40.

Honório, Cláudia. Desvirtuamento do Regime de Emprego (Trabalho Autônomo). In: VIEIRA, Paulo Joarês (org.). Manual de Apoio: Inconstitucionalidades da Lei $\mathrm{n}^{\circ}$. 13.467/2017. Ministério Público do Trabalho, p. 12-16.

$2^{\text {a }}$. Jornada de Direito Material e Processual do Trabalho. Enunciados Aprovados na

$2^{a}$. Jornada. Disponível em: http://www.jornadanacional.com.br/listagemenunciados-aprovados-vis1.asp. Acesso em: 6 jul. 2019.

Krein, José Dari et al. (2018). Flexibilização das relações de trabalho: insegurança para os trabalhadores. In: Krein, José Dari; Gimenez, Denis Maracci; Santos, Anselmo Luis dos (org.). Dimensões Críticas da Reforma Trabalhista no Brasil. Campinas: Curt Nimuendajú, p. 104-105.

Melo, Carmem Cenira Pinto Lourena. (2019). A Subordinação Jurídica na Reforma Trabalhista. In: Silva Filho, Carlos Fernando da; Jorge, Rosa Maria Campos; Rassy, Rosângela Silva (org.). Reforma Trabalhista: uma reflexão dos Auditores-Fiscais do Trabalho sobre os efeitos da Lei n. 13.467/2017 para os trabalhadores. São Paulo: Ltr, p. 76-81.

Organização Internacional do Trabalho. Recomendação $n^{o}$. 198, de 15 de junho de 2006 - Recomendação do Relacionamento Empregatício. Disponível em: 
https://www.legistrab.com.br/recomendacao-oit-198-relativa-a-relacao-de-trabalho. Acesso em: 16 jul. 2019.

Portal de Notícias G1. Senado aprova reforma trabalhista; texto segue para sanção de Temer. Disponível em: https://g1.globo.com/politica/noticia/apos-sessaotumultuada-senado-aprova-texto-base-da-reforma-trabalhista.ghtml. Acesso em: 7 jul. 2019.

Portal do Empreendedor. Como eu faço para abrir um Microempreendedor Individual - MEI? Disponível em: https://www.portaldoempreendedor.gov.br/duvidas-mais-sobre-o-mei/as-duvidasmais-frequentes-sobre-o-microemprendedor-individual/2-como-eu-faco-para-abrirum-microempreendedor-individual-mei. Acesso em: 14 jul. 2019.

Porto, Lorena Vasconcelos. (2009). A subordinação no contrato de trabalho. Uma releitura necessária. São Paulo: LTr, p. 253.

Rádio Câmara. Reforma Trabalhista: teletrabalho e autônomo exclusivo - Bloco 8. Disponível em: https://www2.camara.leg.br/camaranoticias/radio/materias/REPORTAGEMESPECIAL/561197-REFORMA-TRABALHISTA-TELETRABALHO-EAUTONOMO-EXCLUSIVO-BLOCO-8.html. Acesso em: 6 jul. 2019.

Saad, José Eduardo Duarte. Tabela das ADINs - Reforma Trabalhista. Disponível em: $\quad$ http://www.saadadvocacia.com.br/publicacoes/noticias/69-tabela-das-adinsreforma-trabalhista. Acesso em: 6 jul. 2019.

Sales, Bruno Pontes. Subordinação no Pós-Reforma: a Necessidade de Retorno à Dependência como Pressuposto Autêntico do Liame de Emprego. In: Silva Filho, Carlos Fernando da; Jorge, Rosa Maria Campos; Rassy, Rosângela Silva (org.). Reforma Trabalhista: uma reflexão dos Auditores-Fiscais do Trabalho sobre os efeitos da Lei n. 13.467/2017 para os trabalhadores. São Paulo: Ltr, 2019, pp. 53-75.

Severo, Valdete Souto; Souto Maior, Jorge Luiz. (2017) Manual da Reforma Trabalhista: pontos e contrapontos. São Paulo: Sensus, p. 38-43.

Silva, Homero Batista Mateus da. (2015). Curso de Direito do Trabalho Aplicado Vol. 1: Parte Geral. São Paulo: Revista dos Tribunais, p. 21-22.

Sousa, Valdivino. Pejotização agrava problema e previdência perde contribuintes mais ricos. Disponível em: https://valdivinodesousa.jusbrasil.com.br/noticias/532769468/pejotizacao-agravaproblema-e-previdencia-perde-contribuintes-mais-ricos. Acesso em: 6 jul. 2019.

Vieira, Paulo Joarês et al. Trabalhador Autônomo "Exclusivo". In: Carelli, Rodrigo de Lacerda; Cunha, Tadeu Henrique Lopes da (org.). Manual de Apoio: Prestação de

Laborare. Ano II, Número 3, Jul-Dez/2019, pp. 81-105. ISSN 2595-847X. https://trabalhodigno.org/laborare DOI: https://doi.org/10.33637/2595-847x.2019-36 
Serviços, "Pejotização" e Autônomo. Coordenadoria Nacional de Combate às Fraudes nas Relações de Trabalho (CONAFRET) do Ministério Público do Trabalho, p. 82-85.

Welle, Arthur et al. (2018). Reforma Trabalhista e Financiamento da Previdência Social: simulação dos impactos da pejotização e da formalização. In: Krein, José Dari; Gimenez, Denis Maracci; Santos, Anselmo Luis dos (org.). Dimensões Críticas da Reforma Trabalhista no Brasil. Campinas: Curt Nimuendajú, p. 295.

Recebido: 22/07/2019

Revisado: 27/08/2019

Aprovado: 05/10/2019 